\title{
Effects of luminance oscillations on simulated lightness discriminations
}

\author{
STEVEN S. SHIMOZAKI and JAMES P. THOMAS \\ University of California, Los Angeles, California \\ and \\ MIGUEL P. ECKSTEIN \\ University of California, Santa Barbara, California
}

\begin{abstract}
The speed of processes underlying lightness constancy was studied by having observers discriminate small differences in simulated lightness under an oscillating illumination. The period of oscillation varied from 0.25 to $120 \mathrm{sec}$. The target was a $1^{\circ}$ square which appeared for $150 \mathrm{msec}$ at random intervals either directly against a uniform background or separated from the background by a $1^{\circ}$ dark gap. When the target and background were adjacent to each other, discrimination accuracy approached control levels (fixed illumination) at all but the shortest periods of oscillation. When the gap was introduced, accuracy increased as the period of oscillation increased, but never approached control levels. The results suggest that a fast local contrast mechanism is the primary mediator of lightness constancy for this task, but that there is also a slower mechanism that may be related to adaptation.
\end{abstract}

Estimating the surface color of an object can be a difficult computational problem, because the light reflected from an object is a function of the surface reflectance properties of the object and the spectral properties of the illumination. However, we have some ability to discount the effect of the illumination on the reflected light, and we generally perceive the surface properties of an object (e.g., Arend \& Goldstein, 1987; Land, 1959a; McCann, McKee, \& Taylor, 1976). The problem of estimating the surface properties of an object is known as color constancy. A special case of color constancy is the estimation of surface reflectances that vary only along the dimension of luminance. For example, in a scene with only black, gray, and white surfaces, there is only a single neutral, or achromatic, chromaticity. The visual system still must estimate the percentage of light reflected from a surface to assign a reflectance value to the surface whether it is a black, gray, or white surface or an illumination source. This special case of color constancy is known commonly as lightness or achromatic constancy.

The goal of these experiments was to examine the rapidity of the processes that underlie color/lightness constancy. In other words, how fast must the illumination

The authors thank Thomas Wickens, Ione Fine, Philip Kellman, Josef Skrzypek, and Joaquin Fuster for their advice and comments and Lynn Olzak and Harold Stanislaw for their programming assistance. The authors also thank Elizabeth Thurlow, Stephanie Tom, Andra Shimozaki, Michael Hataka, Kevin Tucker, Susan Dawson, Angela Fratianne, Yin Tee, Mandy Yousefmoradi, and Jennifer Fuchs for their participation as observers. This study was part of the first author's Ph. D. dissertation and was supported by Grant EY-00360 from the National Institutes of Health. Correspondence concerning this article should be addressed to S. Shimozaki, Department of Psychology, University of California, Santa Barbara, CA 93106 (shimozak@ psych.ucsb.edu). change before the processes responsible for constancy fail to keep up?

There are some reasons to suspect that temporal limitations on estimating surface properties might be found. One reason is the role that light adaptation might play in estimating surface reflectance. A well-known and simple model of color constancy was proposed by von Kries (1905). This model is based on the multiplicative scaling of the cone inputs, which is inversely proportional to the level of the excitation of the cones caused by the illumination.

Several studies of light adaptation have shown processes with time courses of several seconds (Adelson, 1982; Hayhoe, Benimoff, \& Hood, 1987; Hayhoe, Levin, \& Koshel, 1992; Hayhoe \& Wenderoth, 1991). Typically these processes have been separated into subtractive mechanisms that are analogous to a DC adjustment of the retinal cone signal, and multiplicative mechanisms that are analogous to gain changes of the retinal cone signal (Hayhoe et al., 1987). Most evidence suggests that the subtractive mechanisms are the slower of the processes, though this is not an entirely clear distinction (Hayhoe et al., 1992; Hayhoe \& Wenderoth, 1991).

Another reason for temporal effects may be derived from computational models of color constancy. Any color constancy model must make some assumption about absolute surface reflectance. In computational models of color constancy, there are two common assumptions made to obtain absolute reflectance values. The first assumption is that the object with the highest surface reflectance is white (e.g., Land, 1959b, 1964). The other common assumption is that the space-averaged reflectance of a scene is equal to a neutral surface reflectance, sometimes called the gray world hypothesis (Buchsbaum, 1980; Helson, 1938; Hurlbert, 1986). One proposed mechanism to 
calculate this space-averaged reflectance is through the integration of the individual reflectances in a scene across eye movements (Cornelissen \& Brenner, 1995; D'Zmura \& Lennie, 1986; Fairchild \& Lennie, 1992). Since eye movements occur naturally at a rate of about 3 to 4 per second, coverage of an entire scene may be expected to take several seconds, and consequently any integration process would be relatively slow.

\section{Overview of Experiments}

Observers performed a simulated surface reflectance discrimination task under a simulated oscillating illumination in order to determine how accuracy in the constancy task might vary as a function of the rate of illumination change. As the rate increases, it might be expected that the processes responsible for the reflectance discrimination would be unable to keep up with the illumination change; therefore, performance should decrease as the rate increases. Sinusoidal oscillations of the illumination were used to avoid transients, which might complicate the interpretation of the results.

To focus on the temporal effects, the spatial aspects were kept as simple as possible-one uniform target presented at random intervals against a uniform background. The target was one of two possible targets that differed slightly in simulated reflectance, and the task of the viewer was to identify which target was presented on each occasion. Only the intensity of the simulated illumination was varied during an experimental session. The simulated reflectance of the background differed from the targets, but did not vary over time. We simulated surface reflectances by maintaining a constant luminance ratio between the targets and the background. This is an appropriate simulation for the simplified situation (and only this situation) of coplanar achromatic stimuli under a spatially uniform illumination.

The task used in these experiments simulated a reflectance discrimination, with accuracy as the measure. This use of a discrimination task differs from most experiments on lightness and color constancy, which depend on the description of subjective experience, as in an asymmetric matching paradigm. A task based on accuracy was used in order to avoid possible biases to which a matching task might be subject. Also, several authors have stated the difficulty observers might have in judging separately the perceived surface properties of an object and the perceived total reflected light due to the illumination and the object (Jacobsen \& Gilchrist, 1988; Sewall \& Wooten, 1991; Whittle, 1991). By using a discrimination task, we hoped to avoid this difficulty. Also, this task might be more representative of the functional role of color constancy in identifying objects. For example, such a discrimination might be compared with the visual requirements necessary to evaluate, under different kinds of illumination, whether a fruit is ripe enough to take at a grocery store.

One mechanism hypothesized to be responsible for lightness constancy is some sort of local spatial contrast computation or, in other words, the sensing or computing of the luminance ratio at the edge between the target and background (Shapley, 1986; Wallach, 1948; Whittle \& Challands, 1969). To help separate the effects of a local contrast mechanism from those of other possible mechanisms of lightness constancy, the discrimination task was run under two different conditions (see Figure 1). In one experiment, the target was superimposed directly on the background, allowing both temporal (adaptation) and spatial contrast mechanisms to influence the lightness discrimination. In the other experiment, the effects of spatial (but not temporal) contrast were reduced by introducing a dark gap between the target and the background.

Previous studies have shown that responses to targets can depend on whether the target has a higher or lower luminance than that of the background. The relationship of targets with their background can affect both their appearance (Bonato \& Gilchrist, 1994; Heggelund, 1974) and detectability (Boynton, Ikeda, \& Stiles, 1964; Ehrenstein \& Spillmann, 1983; Patel \& Jones, 1968; Short, 1966). Consequently, two sets of observations were gathered, one with the simulated reflectances (and therefore the luminances) of both targets greater than that of the background and the other with the targets' simulated reflectances (and luminances) lower than that of the background.

Since the simulated illumination was varied over a range of intensities, the luminances of the targets and background also varied over this range. Because the targets differed in simulated reflectance, their luminance ranges differed slightly, creating a possible basis for discrimination. It is unlikely that such a cue would be very useful because the difference was small relative to the range of variation. However, to ensure that such a cue was not being used, control conditions were run in which the reflectance cues for discrimination were removed and the luminance cues for discrimination were maintained.

Another set of control conditions measured performance in a situation in which the simulated illumination did not change during an experimental session. Since the observer did not need to discount any oscillatory change in illumination to perform the task, these control conditions, represent an upper limit of performance for the specific stimulus parameters of this experiment.

\section{METHOD}

\section{Procedure}

For both studies, observers performed a discrimination task between two targets differing slightly in simulated reflectance, and the results were analyzed to derive a measure of accuracy $\left(d^{\prime}\right)$. In Experiment 1 , the targets appeared directly adjacent to the background, and in Experiment 2, the targets appeared against a dark annulus with a width of $1^{\circ}$ placed between the targets and the background (Figure 1).

During a single trial, one of the two targets appeared centrally in the display for $150 \mathrm{msec}$. The two targets were $1^{\circ}$ squares placed on a uniform background. Both targets were either lighter (light targets) or darker (dark targets) than the background, and the targets were identified separately as either the target with the higher or the target with the lower simulated reflectance. Figure 2 displays the time course of a single trial. A trial began with a preparatory tone, 


\section{Experiment 1 \\ No Gap}
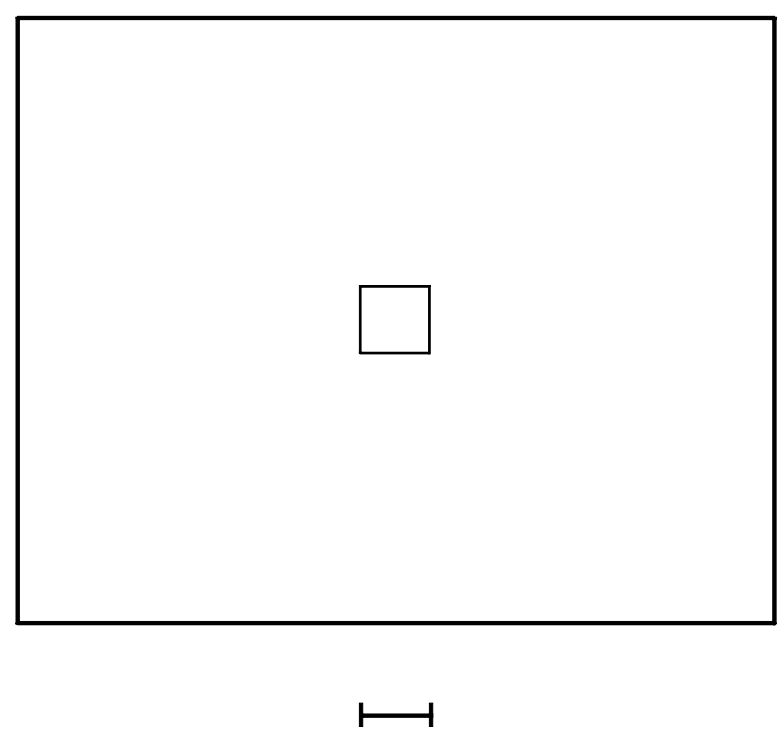

$1 \mathrm{deg}$

\section{Experiment 2 \\ Gap}
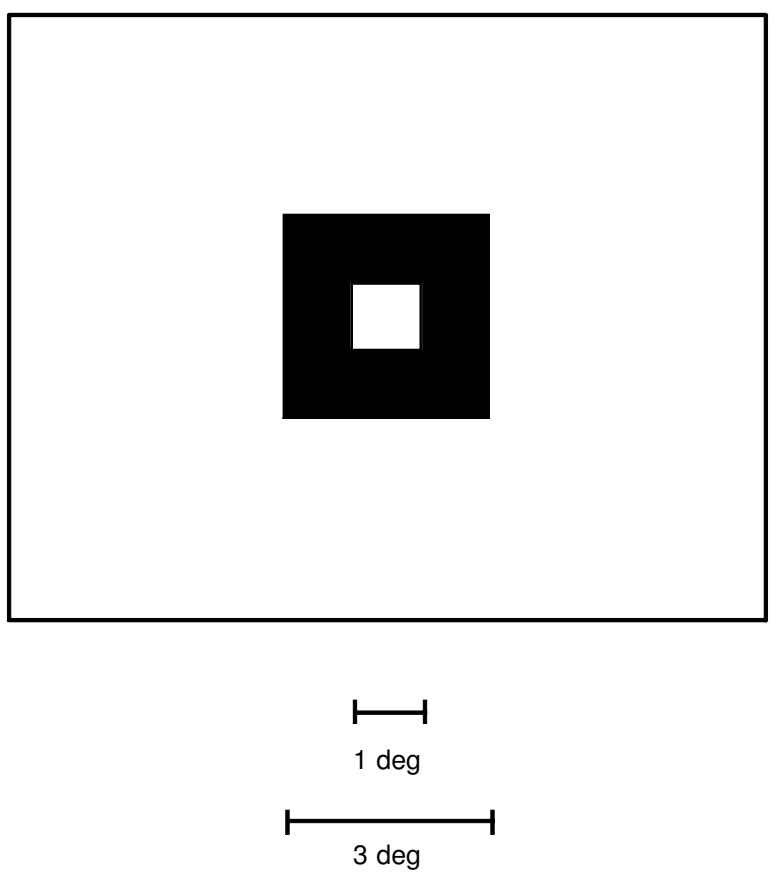

Figure 1. Stimulus configurations for the two experiments. The targets were $1^{\circ}$ squares placed centrally on a uniform background $10^{\circ} \times 12.6^{\circ}$ in visual angle. In the no-gap experiment, the target and the background were directly adjacent to each other. In the gap experiment, a dark annulus was placed between the target and the background. The outside perimeter of the annulus was $3^{\circ} \times 3^{\circ}$, giving a $1^{\circ}$ width of separation between the target and the background.

followed $1 \mathrm{sec}$ later by the presentation of the target for $150 \mathrm{msec}$. The observer's response initiated a feedback tone that indicated the identity of the target appearing during that trial by its pitch. An intertrial interval (ITI) randomly varying from 1 to $2 \mathrm{sec}$ preceded the start of the next trial. Observers viewed the entire uniform background at all times except the target presentation.

Observers indicated which target they thought had appeared during that trial by pressing one of six buttons. These buttons corresponded to a 6-point rating scale that the observers used to make their decisions, combining the identity of the target and the confidence in the decision. The observers were told that the extremes of the rating scale had to represent the highest conf idence ratings for the two targets. For example, the following scale was suggested to the observers: 1 = lighter of the two targets, high confidence, $2=$ lighter of the two targets, medium confidence, $3=$ lighter of the two targets, low confidence, $4=$ darker of the two targets, low confidence, $5=$ darker of the two targets, medium confidence, and $6=$ darker of the two targets, high confidence. The observers were allowed to deviate from the specific designations of this scale as long as their scale also varied continuously from the highest confidence rating for one target to the highest confidence rating for the other target.

Each session comprised 100 responses, 50 for each target, presented in random order. If an observer did not respond within $2 \mathrm{sec}$, that presentation was recycled and presented again later in the ses-

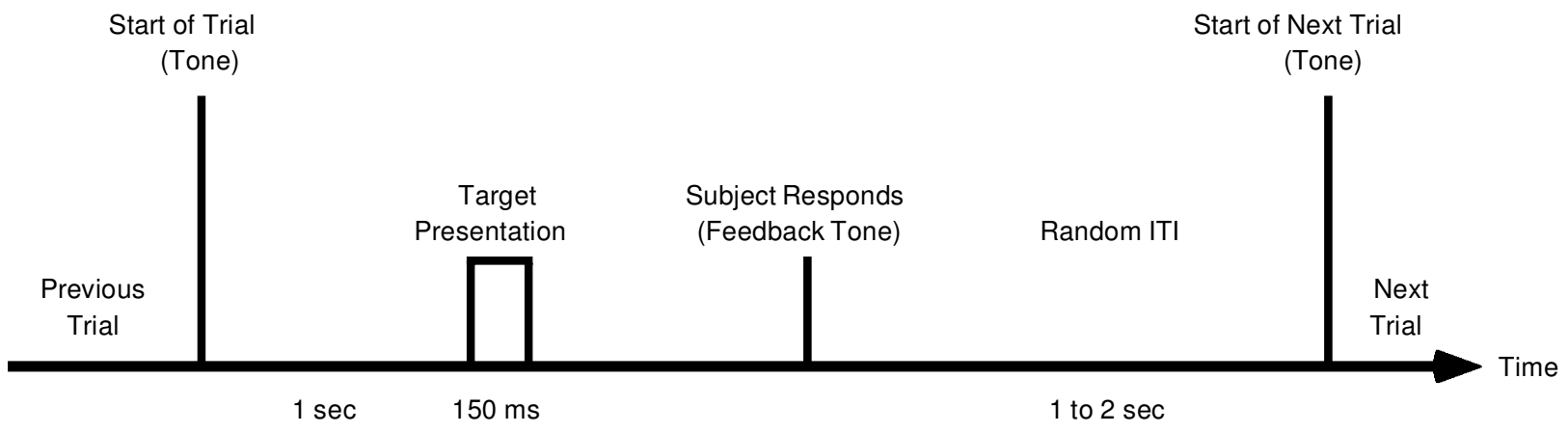

Figure 2. Time course for a single trial. One second after a preparatory tone, the target appeared for $150 \mathrm{msec}$. When the observer responded, a feedback tone was given, indicating the identity of the target for that trial. A random intertrial interval between 1 to 2 sec preceded the next trial. 
sion. The data were analyzed with standard signal detection methods (Green \& Swets, 1966) to derive a single value of $d^{\prime}$ for each session. $\left(d^{\prime}\right.$ is the distance in standard deviations between two hypothetical normal distributions describing the internal representations of the targets. Experimental values of $d^{\prime}$ typically vary from 0 , which is chance performance, to 3 , which is nearly perfect discrimination performance.)

Before the start of each experimental day, the observers darkadapted for $5 \mathrm{~min}$ or more. Before each session, the observers adapted for at least 2 min to the specific simulated illumination conditions of that session. The observers could view each target as many times as they wished before the experiment began, but were required to view either target a minimum of 25 times. The observers observed for 1-2 $\mathrm{h}$, or for 4-8 sessions, per day. The observers alternated running between two blocks of conditions, with one block containing the five luminance control and the two fixed illumination control conditions, and the other block containing the seven temporal oscillations of the oscillating illumination conditions (these conditions are described below). The order of conditions was randomized within each block. Within-observers analyses of variance (ANOVA) were performed on the $d^{\prime}$ values using the statistical package GANOVA (Woodward, Bonett, \& Brecht, 1990) with an alpha level of .05.

The targets were chosen for each observer individually so that performance as measured by $d^{\prime}$ fell within the range of 1.0-1.5 in pilot studies of the fixed illumination control conditions described below. One target was fixed at a Michelson contrast [absolute value of $\left(\mathrm{L}_{\mathrm{t}}-\mathrm{L}_{\mathrm{b}}\right) /\left(\mathrm{L}_{\mathrm{t}}+\mathrm{L}_{\mathrm{b}}\right), \mathrm{L}_{\mathrm{t}}=$ target luminance, $\mathrm{L}_{\mathrm{b}}=$ background luminance] of 0.091 relative to the background, and the contrast for the second target was determined for each observer individually. Table 1 summarizes the observers for both experiments, along with their Michelson contrast values for the second target. All observers were experienced in psychophysical experiments and had normal or corrected-to-normal vision. All observers were naive initially to the purpose of the experiment except for S.S., the first author.

\section{Oscillating Illumination Conditions}

In oscillating illumination conditions, the two targets differed slightly in simulated reflectance, and both the target and the background appeared under conditions simulating an oscillating illumination. The target reflectances were simulated by maintaining a constant relative contrast between the target and the background during the target presentation. The rates of the oscillations were varied in order to assess the ability of the processes responsible for the simulated reflectance judgment to keep up with the oscillations.

The luminance of the background oscillated sinusoidally with a temporal contrast of about one half $(0.523$, or $52.3 \%)$. The minimum, maximum, and mean luminances of the oscillations were $3.43 \mathrm{~cd} / \mathrm{m}^{2}, 10.96 \mathrm{~cd} / \mathrm{m}^{2}$, and $7.19 \mathrm{~cd} / \mathrm{m}^{2}$, respectively. Across ses-

Table 1

Table of Observers and the Michelson Contrasts for the Second Target

\begin{tabular}{lccccc}
\hline & \multicolumn{2}{c}{$\begin{array}{c}\text { Experiment 1 } \\
\text { (No Gap) }\end{array}$} & & \multicolumn{2}{c}{$\begin{array}{c}\text { Experiment 2 } \\
\text { (Gap) }\end{array}$} \\
\cline { 2 - 3 } \multicolumn{1}{c}{ Observer } & Light & Dark & & Light & Dark \\
\hline J.F. (female, 25 years) & .104 & .103 & & \\
S.T. (female, 24 years) & .106 & & & \\
Y.T. (female, 22/23 years) & .106 & .103 & & .111 \\
S.S. (male, 31 years) & & .100 & & .126 & \\
C.W. (female, 22 years) & & & & .130 & \\
E.T. (female, 23 years) & & & & .121 & \\
M.Y. (female, 23 years) & & & & .119 \\
K.T. (male, 23 years) & & & & .119 \\
\hline
\end{tabular}

Note-Michelson contrast $=(\max$ luminance $-\min$ luminance $) /$ (max luminance + min luminance). The first target always had a Michelson contrast of .091. sions, the oscillations were set at seven different periods, $0.25,0.50$, 1.0, 5.0, 10, 30, and $120 \mathrm{sec}$. The rate of oscillation did not change during a session.

The random ITI served to randomize the phase relationship between the occurrence of the targets and the oscillations. This randomized phase relationship also randomized the background and targets' luminances from trial to trial, thus reducing the absolute luminance cues that could be used to perform the task.

\section{Luminance Control Conditions}

Because the targets in the oscillating illumination conditions differed in simulated reflectance, each target had a slightly different range of potential luminances under the oscillating simulated illumination. An equivalent way of expressing this concern is that the two targets had slightly different average luminances over the run of trials in a session. However, on a trial-by-trial basis, these differences were probably insignificant as cues because they were small compared with the variations in luminances produced by the simulated illumination oscillation. Nevertheless, control observations were made to assess the possibility that such differences were being used as cues. In the luminance control conditions, the luminance of the background was fixed at the mean of the oscillations of the background in the oscillating illumination conditions $(7.19 \mathrm{~cd} /$ $\mathrm{m}^{2}$ ). The luminances of the targets were the same as in the oscillating illumination conditions so that they would vary as if illuminated by an oscillating illumination. Thus, the luminance cues from the oscillating illumination conditions were retained in the luminance control conditions, while the simulated reflectance cues (relative contrast) were removed. In effect, the luminance control conditions simulated a situation with two illuminations - a fixed illumination on the background and an oscillating illumination on the targets. The periods of oscillation for the simulated illumination on the targets were $0.25,1,10,30$, and $120 \mathrm{sec}$, matching five out of the seven periods used for the oscillating illumination conditions.

\section{Fixed Illumination Control Conditions}

The fixed illumination control conditions were performed as an estimate for optimal performance in the oscillating illumination conditions. In these conditions, the luminances of both the targets and the background were fixed throughout the session, simulating a situation with a single fixed illumination. With essentially an infinite period, the observers did not have to discount the effect of any oscillation to perform the judgment, and performance should be optimal in the fixed illumination control conditions. There were two separate fixed illumination conditions, in which the background luminance was fixed at either the minimum (fixed illumination control, low) or the maximum (fixed illumination control, high) luminance for the oscillating background in the oscillating illumination conditions $\left(3.43 \mathrm{~cd} / \mathrm{m}^{2}\right.$ and $\left.10.96 \mathrm{~cd} / \mathrm{m}^{2}\right)$.

\section{Apparatus}

The observers viewed binocularly with natural pupils an RGB monitor (Barco ICD-451B, $60 \mathrm{~Hz}$ ) driven by an ATVista Board from TrueVision (32 bit color, 4 channels, 8 bits/per channel) on an IBM-compatible computer (Axik 486 DX66, Cupertino, CA). The viewing size of the monitor was $37 \times 27 \mathrm{~cm}$, which at a viewing distance of $154 \mathrm{~cm}$ gave a display subtending $10^{\circ} \times 12.6^{\circ}$ of visual angle.

Outputs of two of the three channels of the video board were summed through a resistance circuit (Watson et al., 1986), giving a total of 16-bit resolution ( 2 channels $\times 8$ bits/channel) for the single gun. For instrumental reasons, the chromaticity of the display was green, rather than achromatic (CIE coordinates of $x=0.213$, $y=0.623,14.84 \mathrm{~cd} / \mathrm{m}^{2}$ ).

Calibrations were performed with a Spectra Pritchard photometer (Model 1970-PR) calibrated with a standard illuminant (100 Footlambert Gamma Model 220 Standard Lamp source A, tung- 
sten, color temperature $2854 \mathrm{~K}, 342.6 \mathrm{~cd} / \mathrm{m}^{2}$ ). Luminances for 64 gun values were measured and fit to polynomial and logarithmic polynomial functions similar to gamma functions, as described in Stanislaw and Olzak (1990).

The sinusoidal oscillations of the background and targets were approximated by small discrete luminance steps at $60 \mathrm{~Hz}$ (the rate of the monitor), which were undetectable for all modulation periods. The largest luminance change in a single step (which occurred during the $0.25-\mathrm{sec}$ period condition) was $1.53 \mathrm{~cd} / \mathrm{m}^{2}$.

\section{Experiment 1: \\ No Gap}

In this experiment, all targets were $1^{\circ}$ squares directly adjacent to the background (Figure 1). The observers performed eight repetitions of each oscillating illumination, fixed illumination control, and luminance control conditions.

\section{Results and Discussion}

Figures 3 and 4 give the results for the no gap studies, with the individual data on the right column and the collapsed data on the left. Figure 3 gives the results for the light targets, and Figure 4 gives the results for the dark targets. The circles represent the oscillating illumination conditions, the triangles the luminance control conditions, and the arrowed lines the fixed illumination control conditions. The error bars for the collapsed data indicate the standard errors of the mean between observers.

Performance in all the luminance control conditions is near zero, suggesting that the observers could not use the small differences in average luminance as cues in the oscillating illumination conditions. This indicates that, as expected, performance in the oscillating illumination conditions was related to the simulated reflectance differences of the targets and not to the small luminance differences.

For the light targets (Figure 3), performance in the oscillating illumination conditions approached the levels of the fixed illumination control conditions at all periods of oscillation, suggesting that the mechanisms responsible for constancy are fast enough to adjust for even the most rapid oscillations used. A different pattern was found for the dark targets (Figure 4). Although performance in the oscillating illumination conditions was greater than that in the luminance control conditions for all periods tested, a gradual increase in performance was found for periods of up to $5 \mathrm{sec}$. The difference between the light and dark targets was significant, as is indicated by the interaction between the type of target (light or dark) and period collapsed over all observers $[F(6,252)=4.494$, $\left.M S_{\mathrm{e}}=0.074, p=.0002\right]$.

Despite the difference in the pattern of results, the results for both the light and dark targets in the oscillating illumination conditions approached the levels of performance in the fixed illumination control conditions. Thus, with edge contrast information, the processes responsible for the reflectance judgments can account fully for the simulated illumination oscillations. For the light targets, this included all the periods tested, and for the dark tar- gets, this included oscillations of periods of $5 \mathrm{sec}$ and greater.

For the fixed illumination control conditions with the light targets, performance in the high luminance condition (FIC-high) was consistently higher than in the low luminance condition (FIC-low). The reason for this result is unclear, and this pattern did not appear consistently in the other studies.

\section{Experiment 2: \\ Gap}

As suggested by various authors (Shapley, 1986; Wallach, 1948; Whittle \& Challands, 1969), an important cue for the estimation of surface colors is the edge contrast between objects. In the second experiment, we attempted to remove the effect of this cue by placing a dark annulus between the target and the background (Figure 1). The annulus appeared only when the target was displayed, and the size of the outside border with the background was $3^{\circ} \times 3^{\circ}$, giving an annulus width of $1^{\circ}$ around the target. Because the annulus was dark, the edge contrasts between the annulus and the target, and the annulus and the background, were uninformative for performing the simulated reflectance task. As in Experiment 1, the studies for light and dark targets (relative to the background) were performed separately.

The stimulus conditions simulated conditions in which a void is placed between the target and the background. These conditions are similar to those illustrating the Gelb effect (Gelb, 1929), in which targets are placed in a void with an illumination shining only on the target. The difference in this case was the presence of the background surrounding the void and the presence of background at the target location between stimulus presentations.

The luminance of the annulus was set to the lowest value of the summed 16-bit look-up table (LUT) of the graphics board controlling the monitor (less than $0.1 \mathrm{~cd} /$ $\mathrm{m}^{2}$ ). All observers performed 10 repetitions of each condition, except for C.W., who participated in 9 repetitions.

\section{Results and Discussion}

Figures 5 and 6 give the results with the gap, with the individual data to the right and the collapsed data to the left. Figure 5 shows the results for the light targets, and Figure 6 shows the results for the dark targets. As in Figures 3 and 4, the circles represent the oscillating illumination conditions, the triangles the luminance control conditions, and the arrowed lines the fixed illumination control conditions.

As in Experiment 1, results for all the luminance control conditions again generally were close to zero, suggesting that the luminance cues in the oscillating illumination conditions could not be used by the observers to perform the task.

The results of both studies with light targets (Figure 5) and dark targets (Figure 6) show a gradual increase in performance with increasing period over the entire range of periods tested. For the collapsed data, results for both 


\section{COLLAPSED ACROSS SUBJECTS}

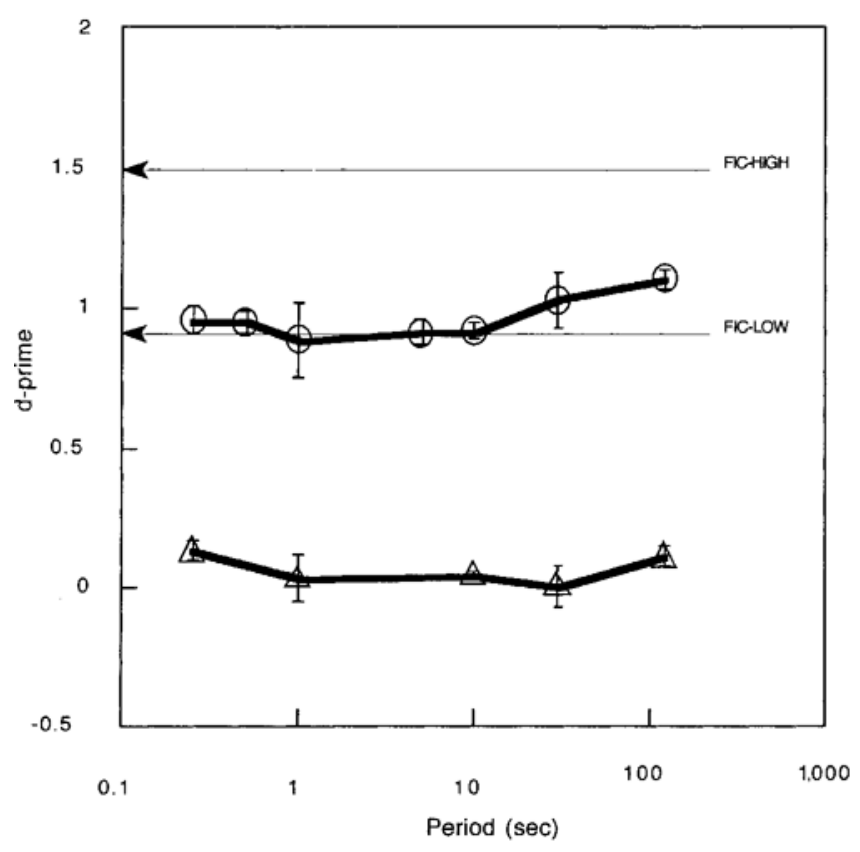

- Oscillating Illumination $\triangle$ - Luminance Control
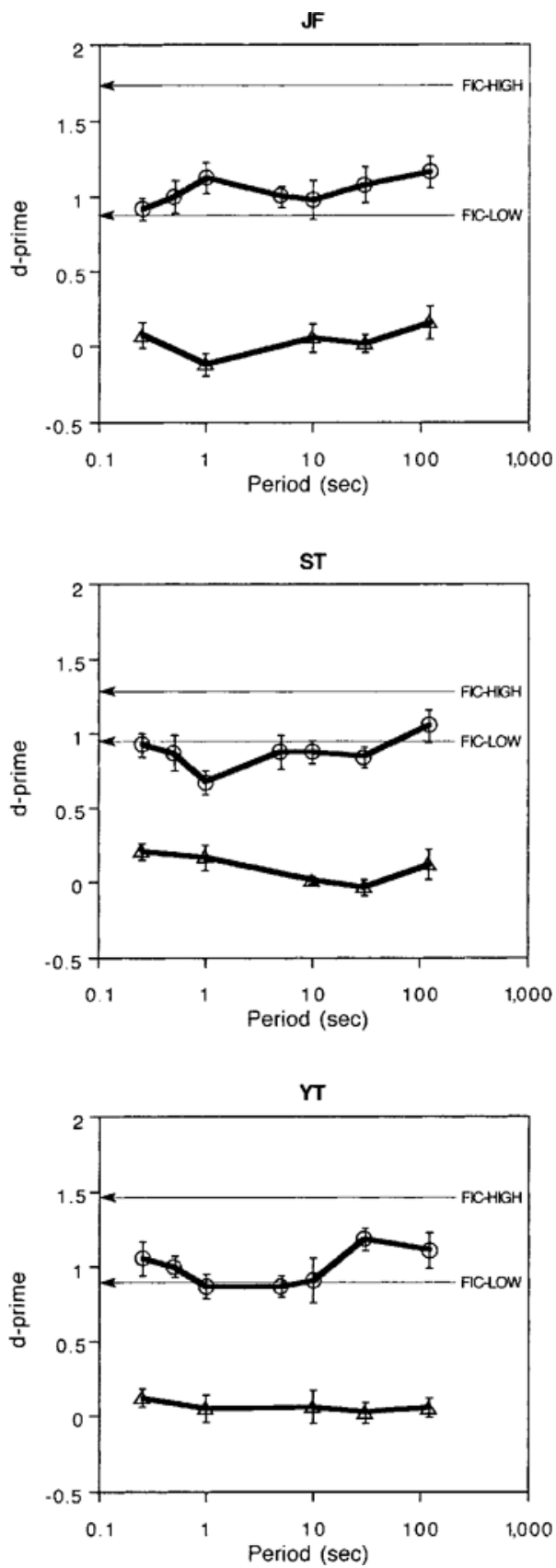

Figure 3. Results for Experiment 1, no gap with light targets condition. The left panel shows the collapsed data, and the right panel shows the individual data. The abscissa is the period of oscillation in seconds, and the ordinate is $d^{\prime}$. The arrowed lines represent the fixed illumination control conditions. The circles represent the oscillating illumination conditions, and the triangles represent the luminance control conditions. FIC-high = fixed illumination control condition with high background luminance. FIC-low = fixed illumination control condition with low background luminance. Error bars indicate the standard errors of the mean between observers.

the light and dark targets had significant linear trends [dark targets, $F(1,27)=27.40, M S_{\mathrm{e}}=0.064, p<.0001$; light targets, $\left.F(1,26)=26.06, M S_{\mathrm{e}}=0.039, p<.0001\right]$. These linear trends did not differ from each other.

Unlike in the previous experiment, performance in the oscillating illumination conditions generally did not ap- proach the levels of performance reached in the fixed illumination control conditions. Maximal performance for all observers, both individually and collapsed across observers, was found typically at the slowest period of oscillation $(120 \mathrm{sec})$ and was about half that reached in the fixed illumination control conditions. This performance 


\section{COLLAPSED ACROSS SUBJECTS}

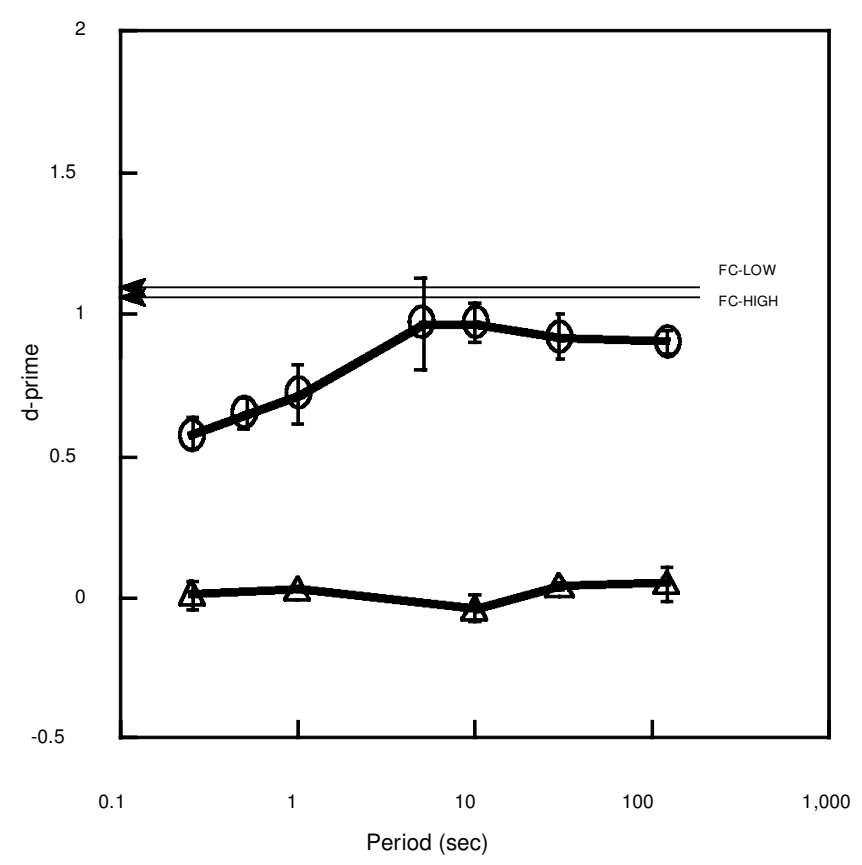

- Oscillating Illumination

$\triangle$ - Luminance Control
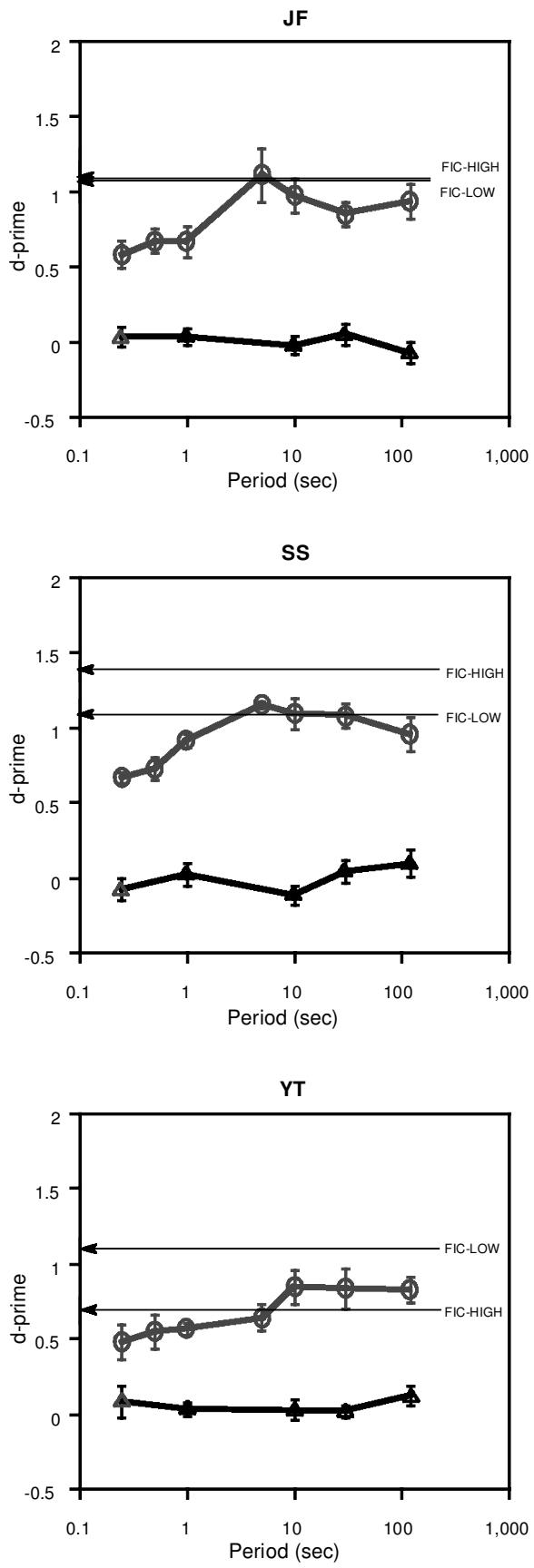

Figure 4. Results for Experiment 1, no gap with dark targets condition. See caption for Figure 3 for details.

differed significantly from that in the fixed illumination control conditions, with the exception of Y.T. with the dark targets and the fixed illumination control condition with low background luminance (FIC-low) (see Table 2 for statistics).

Figure 7 summarizes the results for the oscillating illumination conditions across the two experiments. In the no-gap experiment (Experiment 1, open symbols in Figure 7), the task performance in the oscillating illumination conditions approached the performance in the fixed illumination control conditions, which generally was equal to a $d^{\prime}$ of about 1 (Figures 3 and 4 , collapsed results, arrowed lines). These results suggest that the processes that mediate the constancy judgments in this task can fully discount the effects of the illumination oscillation. These processes are relatively fast, and they appear to be faster for the light targets (circles) than for the dark targets (squares).

In the gap experiment (Experiment 2, filled symbols in Figure 7), performance in the oscillating illumination 
COLLAPSED ACROSS SUBJECTS

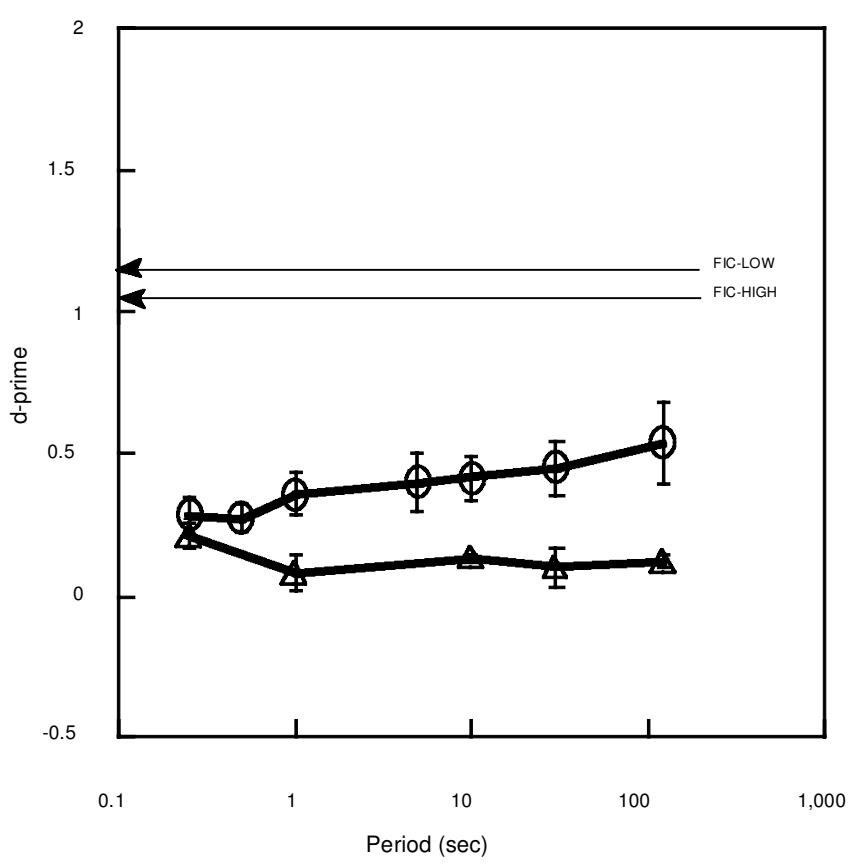

- Oscillating Illumination $\triangle$ - Luminance Control
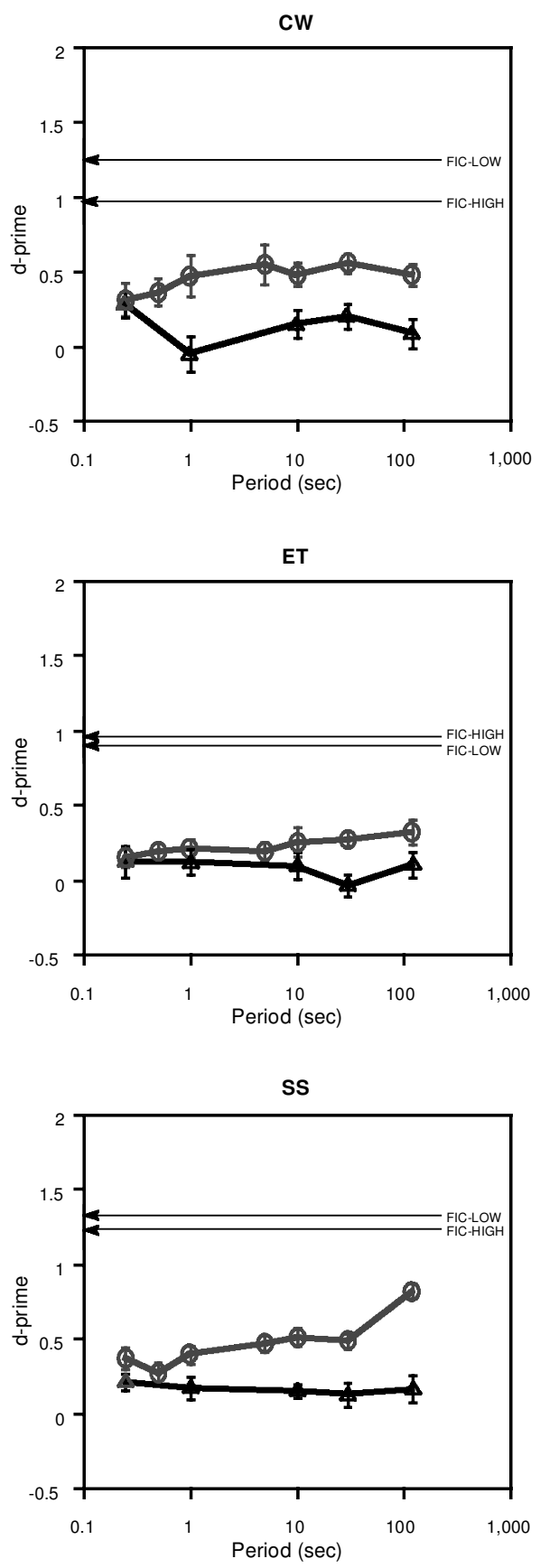

Figure 5. Results for Experiment 2, gap with light targets condition. See caption for Figure 3 for details.

conditions approached about half the level of performance in the fixed illumination control conditions, which again was equal to a $d^{\prime}$ of about 1 (Figures 5 and 6, collapsed results, arrowed lines). Also, performance in the oscillating illumination conditions increased with increasing period throughout the periods tested. These results suggest a slow process that is responsible for the constancy judgment under these conditions.

An ANOVA on the means for each observer confirmed a large gap effect across the two experiments $[F(1,8)=$ $\left.55,56, M S_{\mathrm{e}}=0.100, p<.0001\right]$. Also, a significant gap $\times$ light/dark $\times$ period interaction was found $[F(6,48)=$ $\left.2.913, M S_{\mathrm{e}}=0.008, p=.0167\right]$, which was mostly due to the differential effect of period on the light and dark targets in the no-gap experiment.

\section{GENERAL DISCUSSION}

It appears that introducing the $1^{\circ}$ spatial gap in Experiment 2 made inoperative the fast processes respon- 


\section{COLLAPSED ACROSS SUBJECTS}

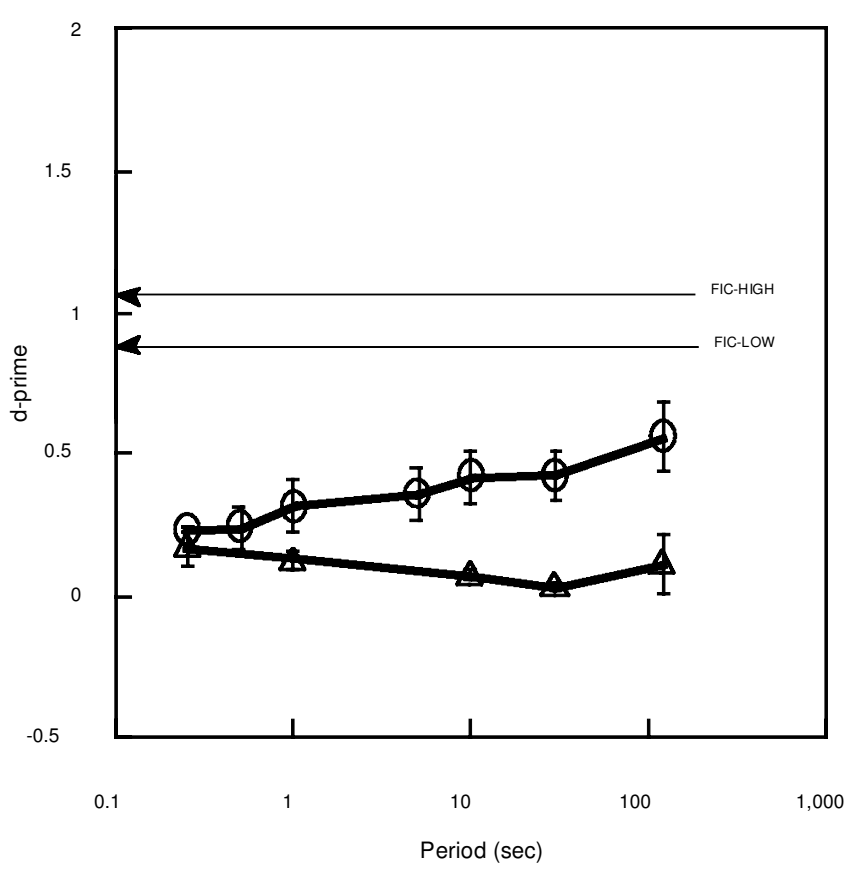

- Oscillating Illumination $\triangle$ - Luminance Control
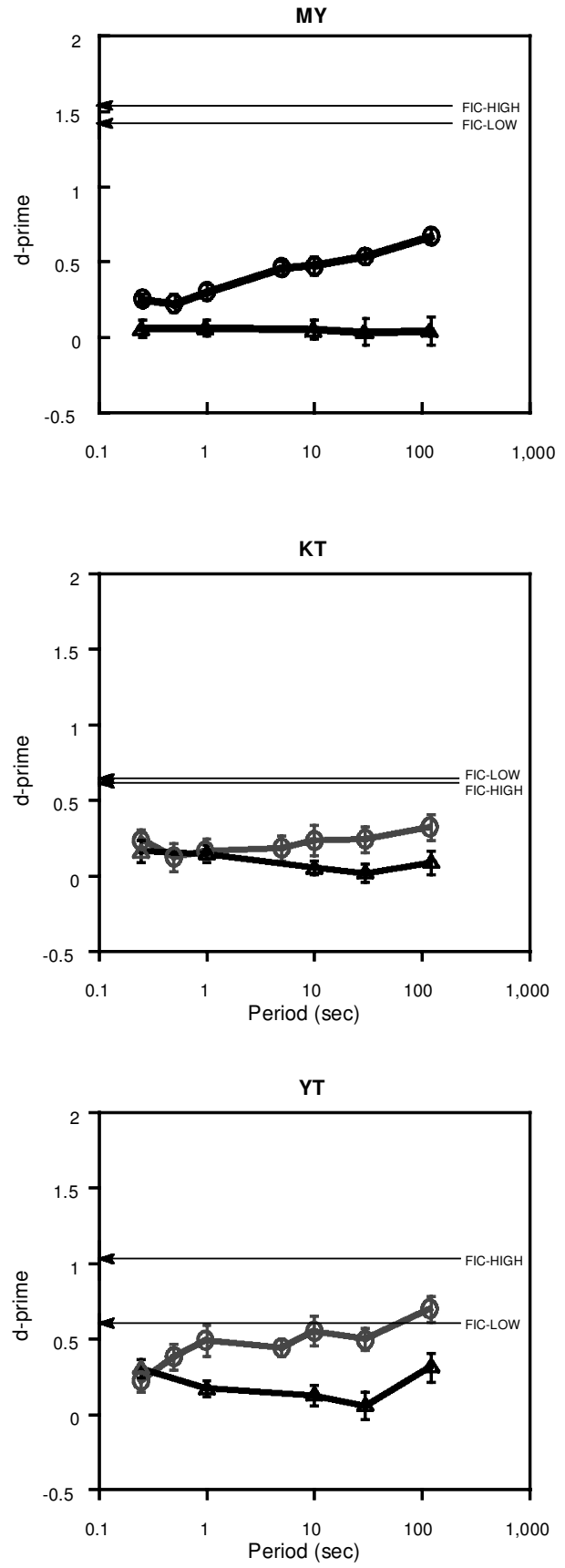

Figure 6. Results for Experiment 2, gap with dark targets condition. See caption for Figure 3 for details.

sible for the judgments without the gap in Experiment 1 . This suggests that spatial edge contrast is an important property for constancy judgments under rapidly changing illumination conditions. As mentioned earlier, such local contrast cues can play a large role in estimating surface color. The underlying mechanism may involve the spatial opponency that characterizes receptive fields at nearly all levels of processing and are considered to be rapid processes.
The insertion of a dark annulus in the gap experiments appears to reveal a slow mechanism that aids in the discounting of illumination changes with respect to surface reflectance judgments. This slower mechanism could be related to adaptation or integration processes necessary to estimate surface reflectance properties of objects discussed earlier. Slower light adaptation mechanisms operating on the order of tens of seconds have been found for both photopic (Hayhoe et al., 1987; Hayhoe et al., 
Table 2

Maximal Performance Versus Fixed Illumination Control Conditions in Experiment 2 (Gap)

\begin{tabular}{|c|c|c|c|c|c|}
\hline \multicolumn{6}{|c|}{ Light Targets } \\
\hline & & C.W. (OI-30) & E.T. & S.S. & Collapsed \\
\hline \multirow[t]{2}{*}{ FIC-low vs. OI-120 } & $F$ values & $16.80(.0034)$ & $8.27(.0021)$ & $36.31(.0002)$ & $65.64(<.0001)$ \\
\hline & $M S_{\mathrm{e}}$ & 0.156 & 0.088 & 0.035 & 0.075 \\
\hline \multirow[t]{2}{*}{ FIC—high vs. OI-120 } & $F$ values & $19.22(.0023)$ & $30.10(.0004)$ & $12.13(.0069)$ & $45.44(<.0001)$ \\
\hline & $M S_{\mathrm{e}}$ & $\begin{array}{l}0.057 \\
d f=1,8\end{array}$ & $\begin{array}{l}0.067 \\
d f=1,9\end{array}$ & $\begin{array}{l}0.065 \\
d f=1,9\end{array}$ & $\begin{array}{l}0.074 \\
d f=1,26\end{array}$ \\
\hline \multicolumn{6}{|c|}{ Dark Targets } \\
\hline & & K.T. & Y.T. & M.Y. & Collapsed \\
\hline \multirow[t]{2}{*}{ FIC-low vs. OI-120 } & $F$ values & $15.02(.0038)$ & & $64.64(<.0001)$ & $41.61(<.0001)$ \\
\hline & $M S_{\mathrm{e}}$ & 0.33 & & 0.042 & 0.036 \\
\hline \multirow[t]{2}{*}{ FIC-high vs. OI-120 } & $F$ values & $8.63(.0166)$ & $5.17(.0491)$ & $30.80(.0004)$ & $40.22(<.0001)$ \\
\hline & $M S_{\mathrm{e}}$ & $\begin{array}{l}0.048 \\
d f=1,9\end{array}$ & $\begin{array}{l}0.102 \\
d f=1,9\end{array}$ & $\begin{array}{l}0.121 \\
d f=1,9\end{array}$ & $\begin{array}{l}0.091 \\
d f=1,27\end{array}$ \\
\hline
\end{tabular}

Note $-p$ values are in parentheses. OI-120 = oscillating illumination condition with 120 -sec periods. OI-30 = oscillating illumination condition with 30-sec periods. FIC-low = fixed illumination control condition with low background luminance. FIC-high = fixed illumination control condition with high background luminance. For C.W., comparisons were made against the oscillating illumination condition with 30sec periods.

1992; Hayhoe \& Wenderoth, 1991) and scotopic (Adelson, 1982) light adaptation, with most of these mechanisms being characterized as subtractive. The role of the slow processes apparent in the gap experiments is unclear under the no-gap viewing conditions, since little change in performance was seen for the slower periods. It is possible that the slower mechanisms are not active normally and are used only when other processes, such as those apparent in the no-gap experiments, have been disrupted.
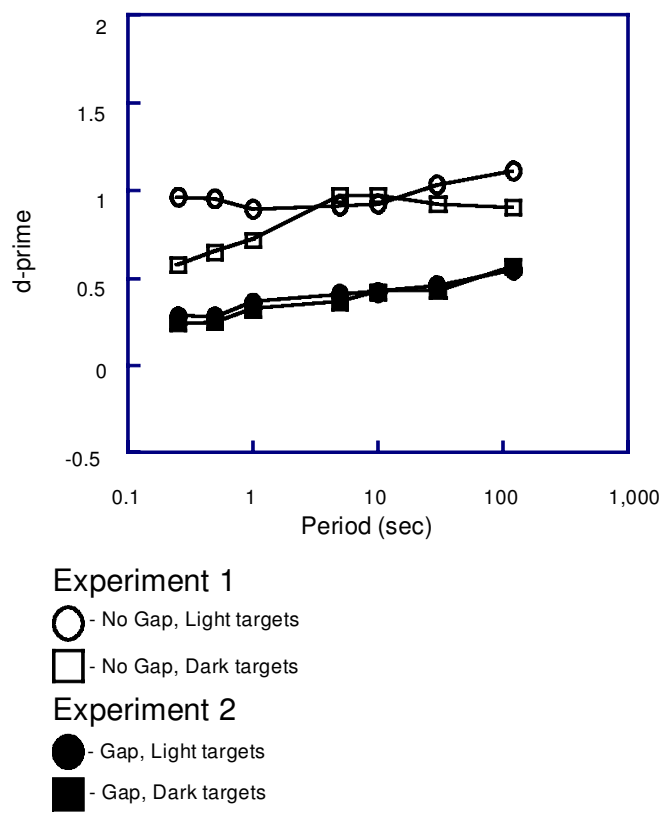

Figure 7. Results collapsed across observers for Experiments 1 and 2 , oscillating illumination conditions. The abscissa is the period of oscillation in seconds, and the ordinate is $d^{\prime}$. Open symbols represent the no-gap experiment, and filled symbols represent the gap experiment. The circles represent the light targets, and the squares represent the dark targets.
It is also possible that the slower processes were active in the no-gap experiments and that their effect was concealed by these other processes.

It should be noted that the $1^{\circ}$ gap affected performance in static conditions without any temporal modulation as well. Pilot studies were used to determine the difference between the two targets needed for $d^{\prime}$ ranging from 1.0 to 1.5 in the fixed illumination control conditions. In these pilot studies, the differences tended to be about two to three times larger for the gap experiments than for the nogap experiments. The difference in performance with and without the gap was confirmed in a control study. Three of the observers (E.T., M.Y., and S.S.) participated in this study, in which the contrast differences between the two targets at threshold were estimated. The conditions were equivalent to fixed illumination control (high) conditions with and without the $1^{\circ}$ spatial gap for both increments and decrements. There was no significant difference found between the thresholds for increments and decrements, but a large difference between the thresholds with and without a gap was found. Estimates of the contrast differences at threshold (defined as $d^{\prime}=1.0$ ) between the two discrimination targets and across the three observers was $3.65 \%$ (standard error $=0.14$ ) with the gap, and $1.42 \%$ (standard error $=0.24$ ) without the gap, approximately the same difference of contrasts used in the gap and no-gap experiments. This is consistent with other studies in which it has been found that such judgments are hindered with the placement of an intervening dark annulus between the target and the background (Shapley \& Tolhurst, 1973; Thomas \& Kovar, 1965; Tolhurst, 1972; Walsh, 1958; Whittle, 1992). Degradations of performance can be found for annuli as small as $6^{\prime}$ of arc, much smaller than the $1^{\circ}$ annulus used in this study.

The present experiment is most similar to the probedsinewave task that was developed by Boynton, Sturr, and Ikeda (1961) and Shickman (1970) and has been used re- 
cently in a number of light-adaptation studies (Hood \& Graham, 1998; Hood, Graham, von Wiegand, \& Chase, 1997; Wolfson \& Graham, 2000, 2001). In the probedsinewave paradigm, the observer must detect a small luminance change (the probe) against a sinusoidally modulating background. The present experiment differs from these experiments in the use of a discrimination task, as opposed to a detection task, and in the placement of the annulus in the gap conditions. Also, longer periods were used in this experiment, from 0.25 to $120 \mathrm{sec}$, compared with the 0.033 to $1 \mathrm{sec}(30$ to $1 \mathrm{~Hz}$ ) range of periods for the other experiments.

Generally, studies of light adaptation that suggest longer adaptation processes have been based on the probe-flash technique (Hood, Ilves, Maurer, Wandell, \& Buckingham, 1978), in which a small and brief luminance test stimulus (the probe) is preceded by an overall step change of the background (the flash). The time course of light adaptation is tested by varying the duration of the flash preceding the probe. Models from this paradigm, in general, describe a fast multiplicative process and both a slow and a fast subtractive process, followed by a static and compressive nonlinearity (e.g., Adelson, 1982; Hayhoe et al., 1987). Also, evidence for both multiplicative and subtractive processes in color appearance have been proposed by studies measuring the effect of the background on a target (induction; Jameson \& Hurvich, 1989; Shevell, 1978; Walraven, 1976).

Another set of light adaptation studies are based on measuring the amplitudes needed to detect the modulation of periodic stimuli and varying the period of the modulation (see Graham, 1989, or Watson, 1986, for a review). Significant findings from this approach are that both the highest frequency modulation that can be detected (the critical flicker frequency) and the temporal frequency with the peak sensitivity increases with increasing illuminance. One model developed by Sperling and Sondhi (1968) is composed of stages of low-pass exponential filters divided into three modules. The first module is a two-stage feedback module that adjusts the speed of its response through its own output (by changing the time constants of the filters). The second module is a one-stage feedforward module with a time constant modified by the output of the first module, and the last module is a six-stage linear low-pass module. Graham and Hood (1992) proposed testing adaptation models from both the probe-flash (or aperiodic) and the periodic paradigms, and their results suggest that neither the models from the probe-flash tradition nor the models from the periodic tradition could account for the results in the opposing tradition. Notably, they proposed adding a subtractive process with a static nonlinearity (as derived from the flash-probe paradigm) into the Sperling and Sondhi model (between the second and third modules) as a hybrid model.

If the frequency of the oscillations were to increase further than the range used in this experiment, we would expect that performance in both the luminance control and the oscillating illumination conditions would increase as well, up to the critical flicker frequency. More of the luminance waveform of the target would appear during the stimulus duration, and the observer would become less sensitive to the oscillation, perceiving only the average luminance of the target. As discussed earlier, the average absolute luminances of the two targets would provide a cue for performing the discrimination task. Consider, for example, that the fixed illumination control stimuli were actually oscillating at a frame rate of $60 \mathrm{~Hz}$ and that both an oscillating illumination and a luminance control condition with the same frequency would be equivalent to the fixed illumination control (except for the amplitude of the oscillation). A hint of this expected improvement can be seen with 0.25 -period $(4 \mathrm{~Hz})$ luminance control data across the experiments and may explain the small increase in performance seen at the smaller periods (higher frequencies) of oscillation with the light targets in the no-gap experiment.

From Figure 7, it appears that performances for the light and dark targets were nearly the same in the gap experiments, whereas the light targets appear to have slightly faster response characteristics than the dark targets in the no gap experiments. The likely reason for the difference in the gap and no-gap experiments is the polarity of the local (edge) contrasts of the targets. In the gap experiments, both the light and dark targets have the same local contrast polarity (positive, or increments) relative to the dark annulus. In the no-gap experiment, the light and dark targets have the opposite local contrast polarity relative to the background, with the light targets having positive polarity (increments) and the dark targets having negative polarity (decrements). Responses to increments and decrements have been shown to differ in a number of tasks.

For example, Heinemann (1955) found that local contrast effects were more pronounced for decrements than for increments, and other studies have found differing detection (Boynton et al., 1964; Patel \& Jones, 1968; Short, 1966) and discrimination (Whittle, 1986) thresholds for decrements and increments, with decrements being slightly better. A recent study done with the probed-sinewave paradigm (Wolfson \& Graham, 2001) also suggests slightly lower thresholds for decrement targets. In terms of lightness judgments, the results seem a little less clear. Arend and Spehar (1993a, 1993b) obtained results that suggest that, in target-surround configurations with an outside border containing a Mondrian pattern (a random array of surfaces), observers are more accurate at judging the lightness of increments. Schirillo (1999a, 1999b) found that increasing the articulation (increasing the number of nontarget surfaces without altering the space-averaged luminance) improved only the lightness judgments of increments, whereas the lightness judgments of decrements were relatively accurate with or without increased articulation. In a study in which the observers judged the lightness of the background (Noguchi \& Kozaki, 1985), those judgments were better when two small white dots were added, 
as opposed to when two small black dots were added. One could interpret this result as the decrements' being easier to judge, since the white dots made the background a decrement relative to the dots.

The differences between increments and decrements may be based on different interpretations of surface properties. For example, a decrement against a uniform background may appear as a black or gray surface, whereas an increment may appear as a light gray or white surface, or as an illuminant, depending on the contrast of the target with the background (Bonato \& Gilchrist, 1994; Heggelund, 1974). Also, increment targets would favor activation of "on-center" receptive fields, and decrement targets would favor "off-center" receptive fields. These two types of receptive fields are distinct anatomically, starting with the bipolar cells of the retina (see Kolb, 1994, for a review), and Schiller, Sandell, and Maunsell (1986) have shown that blocking the activity of the on-center pathway with the glutamate analog APB selectively impairs the detection of increments. One might suspect that the qualitative perceptual differences between illuminations and surfaces (see, e.g., Mausfeld \& Niederee, 1993 ), or the anatomical separation of off-center and oncenter neurons (see Fiorentini, Baumgartner, Magnussen, Schiller, \& Thomas, 1990, or Schiller, 1992, for a review), could lead to psychophysical differences between increments and decrements.

The concept of separable processes for increments and decrements has been used in recent models of adaptation and color appearance. For example, Hood and Graham (1998) implemented a version of Wilson's (1997) light retinal light adaptation model and found that their data were fit well assuming that the off-center pathway was about twice as sensitive as the on-center pathway. Also, Mausfeld and Niederee (1993) developed a model of color appearance for target-surround stimuli based on multiplicative processes for the incremental or decremental signal above or below the surround (similar to Walraven's, 1976, model of discounting the illuminant) that employs separate processes for increments and decrements. A last example is Watson's (1986) model of temporal sensitivity based on probability summation.

Several studies also have suggested different time courses to the adaptation of overall increases and decreases of light intensity ("light" and "dark" adaptation). For photopic light levels, both Poot, Snippe, and van Hateren (1997) and Hayhoe et al. (1987) found that adaptation to decreasing light intensity has a time course ranging from 50 to $100 \mathrm{msec}$ compared with 200 to $800 \mathrm{msec}$ for increasing light intensity. Also, Yeh, Lee, and Kremers (1996) found a slow adaptation process in the magnocellular and parvocellular pathways in LGN that was only apparent with adaptation to increasing light intensity. For scotopic light levels, it is known that adaptation to increasing light intensity is faster than adaptation to decreasing light intensity (see Hood \& Finkelstein, 1986, for a review).

The range of luminance variation in the experiment was about $0.5 \log$ units-a modest amount, given the capa- bilities of the adaptation mechanisms in the visual system. Also, the mean luminance fell within the mesopic range. The lighting conditions, therefore, did not represent the viewing situations under which surface reflectances are determined normally, and the possible effects of light adaptation cannot be distinguished between cone or rod processes. Clearly, it would be instructive to examine the effects of illumination variations under more natural conditions (i.e., with a larger range of photopic luminances). Unfortunately, the equipment limited the range of luminances. It appears that, compared with more natural lighting situations, the luminances used in this experiment could make surface reflectance both harder to determine due to the mesopic level, since contrast sensitivity generally increases with increasing illuminance, and easier to determine due to the limited range of luminances.

A weakness of the study is the lack of consistency of observers across the experiments, making comparisons between experiments more difficult. The main effect of the gap, however, was quite large and consistent across experiments. Unlike performance in the no-gap experiments, performance with the gap in the oscillating illumination conditions did not approach the performance in the steady-state (fixed illumination control) conditions. Also, we believe that the matching of absolute performance across the experiments in the fixed illumination control pilot studies makes the comparisons across experiments more plausible.

In this study, only two coplanar achromatic surfaces, the target and the background, were simulated at one time under a spatially uniform illumination. This simple situation was chosen in order to isolate the effects of oscillation on the mechanisms of adaptation and edge contrast and their roles in maintaining the accuracy of lightness discriminations. However, this situation is extremely sparse compared with a natural viewing environment, excluding potentially important three-dimensional cues such as transparency (Adelson, 1993), perceived depth (Gilchrist, 1977; Schirillo \& Arend, 1995; Schirillo, Reeves, $\&$ Arend, 1990), and illumination gradients caused by shadows (Adelson, 1993; Knill \& Kersten, 1991; Pessoa, Mingolla, \& Arend, 1996). Also, at least two models of color constancy depend on the presence of multiple surfaces (D’Zmura \& Iverson, 1993a, 1993b, 1994; Maloney \& Wandell, 1986), and some studies have suggested that lightness judgments improve with increasing numbers of visible surfaces (Arend \& Spehar, 1993b; Schirillo, 1999b). In particular, there is some question about the observers' interpretations of the target-surround stimulus configuration and whether changes in luminance can be reliably assigned to illumination or surface reflectance changes.

In theory, two possible percepts can be derived from a light reflected from an achromatic object. First, there is the perceived overall light intensity or brightness, and second, there is the perceived surface reflectance or lightness. These two percepts, however, may not be easily distinguished by an observer. In a review of a number of studies, Whittle (1991) argued that the perceptual ambi- 
guity between lightness and brightness led to conflicting results across a number of studies of lightness and brightness perception. He suggested that observers performed along a continuum from pure brightness to pure lightness matching across these studies. In particular, he noted that increments were never matched to decrements in his "brightness" matching study (Whittle \& Challands, 1969), presumably because observers could not overcome the lightness interpretation from the contrast cue of a lighter surface in the case of an increment, and of a darker surface in the case of the decrement. Other authors have also suggested that lightness and brightness are more theoretical constructs than practically separable percepts (Jacobsen \& Gilchrist, 1988; Sewall \& Wooten, 1991). In addition to lightness and brightness, a separate percept suggested by Arend and Spehar (1993a, 1993b) is the apparent local contrast between a target surface and the surrounding surfaces. Their studies suggest that observers can make distinct judgments on the basis of task instructions for these three percepts. In particular, the results of Arend and Spehar (1993a) suggest that lightness and local contrast judgments in the target-uniform surround configuration are equivalent. It should be noted that this equivalence extends not only to the perceptual interpretations, but also to the theoretical interpretations of surface reflectance. For the target-surround configuration, an assumption of constant reflectances under a uniform illumination implies only that the luminance ratio between the target and the surround is constant.

Also, the display in the gap experiment with the dark annulus was highly unnatural, simulating a situation in which a target surface is placed in a dark void with a surrounding background. Aside from the lack of useful local contrast cues, the unusual situation may have accounted for some of the relatively poor performance in this experiment compared with the no-gap experiment. If the background is removed, leaving only the target in the void, surface reflectance and light intensity become completely confounded, and the surface cannot be resolved. Because of this confound, it is plausible that the observer's perception of the lightness and brightness of the target in a void are also confounded. Even though theoretically the addition of the background in the gap experiment should have disambiguated this confound, it is possible that the judgments of surface reflectance might still be adversely affected by an interfering brightness percept caused by the simulated void.

Given the considerations above, it is unclear whether judgments made by the observers were based on their interpretations of lightness, brightness, or apparent local contrast. In the case of lightness and local contrast, this confusion is theoretical, whereas for lightness and brightness, it is more practical. Indeed, part of the motivation for using a discrimination procedure was to avoid such problems in how the observer chooses to interpret the image. Essentially, the observers were not given any instructions on judging the stimulus on the basis of perceived surface reflectance or perceived light intensity, as has been done in other studies. Instead, observers made a discrimination on the aspect of the image that was the equivalent of surface reflectance in the image, regardless of how the observer chose to perform the task. Although this method is a departure from the asymmetric matching task commonly used in studies of lightness and color, we feel that such a method is useful because it reduces the burden on the observer to interpret the stimulus in a particular fashion.

The dynamic nature of the experiment, however, appears to favor the interpretation of the luminance changes as illumination changes. In this study, the changes in luminances occurred continuously and rapidly. As the background was continuously viewed, assigning these changes to reflectance would lead to an interpretation that the surface reflectances of the target and the background were also changing rapidly. Although reflectance changes of the same object can occur (e.g., the ripening of fruit, a chameleon) a priori, such rapid changes seem less likely than rapid changes in illumination. Also, in another study, we found that observers appeared to be biased to maintain the same perceived reflectance of an object over relatively brief presentations (400 msec) (Shimozaki, Eckstein, \& Thomas, 1999).

\section{REFERENCES}

Adelson, E. H. (1982). Saturation and adaptation in the rod system. Vision Research, 22, 1299-1312.

Adelson, E. H. (1993, December 24). Perceptual organization and the judgment of brightness. Science, 262, 2042-2044.

Arend, L. E., \& Goldstein, R. (1987). Simultaneous constancy, lightness, and brightness. Journal of the Optical Society of America A, 4, 2281-2285.

Arend, L. E., \& Spehar, B. (1993a). Lightness, brightness, and brightness contrast: 1. Illuminance variation. Perception \& Psychophysics, 54, 446-456.

Arend, L. E., \& Spehar, B. (1993b). Lightness, brightness, and brightness contrast: 2. Reflectance variation. Perception \& Psychophysics, 54, 457-468.

Bonato, F., \& Gilchrist, A. L. (1994). The perception of luminosity on different backgrounds and in different illuminations. Perception, 23, 991-1006.

Boynton, R. M., IKedA, M., \& Stiles, W. S. (1964). Interactions among chromatic mechanisms as inferred from positive and negative increment thresholds. Vision Research, 4, 87-117.

Boynton, R. M., Sturr, J. F., \& IKedA, M. (1961). Study of flicker by increment threshold technique. Journal of the Optical Society of America, 51, 196-201.

BuchsBaum, G. (1980). A spatial processor model for object colour perception. Journal of the Franklin Institute, 310, 1-26.

Cornelissen, F. W., \& Brenner, E. (1995). Simultaneous colour constancy revisited: An analysis of viewing strategies. Vision Research, 35, 2431-2448.

D'Zmura, M., \& Iverson, G. (1993a). Color constancy I. Basic theory of two-stage linear recovery of spectral descriptions for lights and surfaces. Journal of the Optical Society of America A, 10, 2148-2165.

D'Zmura, M., \& Iverson, G. (1993b). Color constancy II. Basic theory of two-stage linear recovery of spectral descriptions for lights and surfaces. Journal of the Optical Society of America A, 10, 2166-2180.

D'Zmura, M., \& Iverson, G. (1994). Color constancy III. Basic theory of two-stage linear recovery of spectral descriptions for lights and surfaces. Journal of the Optical Society of America A, 11, 2398-2400.

D'Zmura, M., \& LenNie, P. (1986). Mechanisms of color constancy. Journal of the Optical Society of America A, 3, 1662-1672.

Ehrenstein, W. H., \& Spillmann, L. (1983). Time thresholds for increments and decrements in luminance. Journal of the Optical Society of America, 73, 419-426. 
FAirchild, M. D., \& Lennie, P. (1992). Chromatic adaptation to natural and incandescent illuminants. Vision Research, 32, 2077-2085.

Fiorentini, A., Baumgartner, G., Magnussen, S., Schiller, P., \& Thomas, J. P. (1990). The perception of brightness and darkness. In L. Spillmann \& J. Werner (Eds.), Visual perception: The neurophysiological foundations (pp. 129-161). San Diego: Academic Press.

Gelb, A. (1929) Die "Farbenkonstanz" der Sehdinge. In A. Bethe, G. Bergmann, G. Embden, \& A. Ellinger (Eds.), Handbuch der normalen und pathologischen Phsyiologie 12 (I, pp. 594-678). Berlin: Springer-Verlag.

Gilchrist, A. L. (1977, January 14). Perceived lightness depends on perceived spatial arrangement. Science, 195, 185-187.

GraHAm, N. (1989). Visual pattern analyzers. New York: Oxford University Press.

GraHAM, N., \& Hood, D. C. (1992). Modeling the dynamics of light adaptation: The merging of two traditions. Vision Research, 32, 1373-1393.

GREen, D., \& SwETS, J. (1966). Signal detection theory and psychophysics. New York: Kreiger.

Hay hoe, M. M., Benimoff, N., \& Hood, D. C. (1987). The time course of multiplicative and subtractive adaptation process. Vision Research, 27, 1981-1996.

Hay hoe, M. M., Levin, M., \& . Koshel, R. (1992). Subtractive processes in light adaptation. Vision Research, 32, 323-333.

Hay hoe, M. M., \& Wenderoth, P. (1991). Adaptation mechanisms in color and brightness. In A. Valberg \& B. Lee (Eds.), From pigments to perception: Advances in understanding visual processes (pp. 353369). New York: Plenum.

Heggelund, P. (1974). Achromatic color vision I: Perceptive variables of achromatic colors. Vision Research, 14, 1071-1079.

Heinemann, E. G. (1955). Simultaneous brightness induction as a function of inducing-and test-field luminances. Journal of Experimental Psychology, 50, 89-96.

HeLson, H. (1938). Fundamental problems in color vision. I. The principle governing changes in hue, saturation, and lightness of non-selective samples in chromatic illumination. Journal of Experimental Psychology, 23, 439-476.

Hood, D. C., \& Finkelstein, M. (1986). Sensitivity to light. In K. R. Boff, L. Kaufman, \& J. P. Thomas, (Eds.), Handbook of perception and human performance: Vol. 1. Sensory processes and perception (pp. 5-1 to 5-66). New York: Wiley.

Hood, D. C., \& Graham, N. (1998). Threshold fluctuations on temporally modulated backgrounds: A possible physiological explanation based upon a recent computational model. Visual Neuroscience, 15, 957-967.

Hood, D. C., Graham, N., von Wiegand, T. E., \& Chase, V. M. (1997). Probed-sinewave paradigm: A test of models of light-adaptation dynamics. Vision Research, 37, 1177-1191.

Hood, D. C., Ilves, T., Maurer, E., Wandell, B., \& Buckingham, E. (1978). Human cone saturation as a function of ambient intensity: A test of models of shifts in the dynamic range. Vision Research, 18, 983-993.

Hurlbert, A. (1986). Formal connections between lightness algorithms. Journal of the Optical Society of America A, 3, 1684-1693.

JACOBSEN, A., \& GILChrist, A. (1988). The ratio principle holds over a million-to-one range of illumination. Perception \& Psychophysics, 43, 1-6.

JAMESON, D., \& Hurvich, J. (1989). Essay concerning color constancy. Annual Review of Psychology, 40, 1-22.

Knill, D. C., \& Kersten, D. (1991). Apparent surface curvature affects lightness perception. Nature, 351, 228-230.

KoLB, H. (1994). The architecture of functional neural circuits in the vertebrate retina: The Proctor lecture. Investigative Ophthalmology \& Visual Science, 35, 2385-2404.

KRIES, J. vON (1905) Die Gesichtsempfindungen [The sense of vision] In W. Nagel (Ed.), Handbuch der Physiologie der Menschen (pp. 109282). Brunswick: Wieweg.

Land, E. (1959a). Color vision in the natural image: Part 1. Proceedings of the National Academy of Sciences, 45, 116-129.

LAND, E. (1959b). Color vision in the natural image: Part 2. Proceedings of the National Academy of Sciences, 45, 636-644.

LAND, E. (1964). The retinex. American Scientist, 52, 247-264.
Maloney, L., \& WAndell, B. (1986). Color constancy: A method for recovering surface spectral reflectance. Journal of the Optical Society of America A, 3, 29-33.

Mausfeld, R., \& Niederee, R. (1993). An inquiry into relational concepts of colour, based on incremental principles of colour coding for minimal relational stimuli. Perception, 22, 427-462.

McCann, J., McKee, S., \& TAY lor, T. (1976). Quantitative studies in retinex theory: A comparison between theoretical predictions and observer responses to the "color Mondrian" experiments. Vision Research, 16, $445-458$.

Noguchi, K., \& Kozaki, A. (1985). Perceptual scission of surfacelightness and illumination: An examination of the Gelb effect. Psychological Research, 47, 19-25.

Patel, A. S., \& Jones, R. W. (1968). Increment and decrement visual thresholds. Journal of the Optical Society of America, 58, 696-699.

Pessoa, L., Mingolla, E., \& Arend, L. E. (1996). The perception of lightness in 3-D curved objects. Perception \& Psychophysics, 58, 1293-1305.

Poot, L., Snippe, H. P., \& van Hateren, J. H. (1997). Dynamics of adaptation at high luminances: Adaptation is faster after luminance decrements than after luminance increments. Journal of the Optical Society of America A, 14, 2499-2508.

Schiller, P. H. (1992). The ON and OFF channels of the visual system. Trends in Neurosciences, 15, 86-92.

Schiller, P. H., SAndell, J. H., \& Maunsell, J. H. R. (1986). Functions of the $\mathrm{ON}$ and OFF channels of the visual system. Nature, 322, 824-825.

SCHIRILlo, J. A. (1999a). Surround articulation: I. Brightness judgments. Journal of the Optical Society of America A, 16, 793-803.

SCHIRILLO,J. A. (1999b). Surround articulation: II. Lightness judgments. Journal of the Optical Society of America A, 16, 804-811.

Schirillo, J. A., \& Arend, L. E. (1995). Illumination change at a depth edge can reduce lightness constancy. Perception \& Psychophysics, 57, 225-230.

Schirillo, J. [A.], Reeves, A., \& Arend, L. [E.] (1990). Perceived lightness, but not brightness, of achromatic surfaces depends on perceived depth information. Perception \& Psychophysics, 48, 82-90.

SeWAll, L., \& Wooten, B. R. (1991). Stimulus determinants of achromatic constancy. Journal of the Optical Society of America A, 8 , 1794-1809.

SHAPLEY, R. M. (1986). The importance of contrast for the activity of single neurons, the VEP and perception. Vision Research, 26, 45-61.

Shapley, R. M., \& Tolhurst, D. J. (1973). Edge detectors in human vision. Journal of Physiology, 229, 165-183.

SHEVELL, S. K. (1978). The dual role of chromatic backgrounds in colour perception. Vision Research, 18, 1649-1661.

ShickMan, G. M. (1970). Visual masking by low-frequency sinusoidally modulated light. Journal of the Optical Society of America, 60, 107-117.

Shimozaki, S. S., Eckstein, M. [P]., \& Thomas, J. P. (1999). The maintenance of the apparent luminance of an object. Journal of Experimental Psychology: Human Perception \& Performance, 25, 1433-1453.

Short, A. D. (1966). Decremental and incremental visual thresholds. Journal of Physiology, 185, 646-654.

Sperling, G., \& SondHI, M. M. (1968). Model for visual luminance discrimination and flicker detection. Journal of the Optical Society of America, 58, 1133-1145.

Stanislaw, H., \& OlzaK, L. A. (1990). Parametric methods for gamma and inverse gamma correction, with extension of halftoning. Behavior Research Methods, Instruments, \& Computers, 22, 402-408.

Thomas, J. P., \& Kovar, C. W. (1965). The effect of contour sharpness on perceived brightness. Vision Research, 5, 559-564.

Tolmurst, D. J. (1972). On the possible existence of edge detector neurones in the human visual system. Vision Research, 12, 797-804.

WALLACH,H. (1948). Brightness constancy and the nature of achromatic colors. Journal of Experimental Psychology, 38, 310-324.

WALRAVEN,J. (1976). Discounting the background: The missing link in the explanation of chromatic induction. Vision Research, 16, 289-295.

WALSH, J. W. T. (1958). Photometry (3rd ed.). London: Constable.

Wat son, A. B. (1986). Temporal sensitivity. In K. R. Boff, L. Kaufman, 
\& J. P. Thomas (Eds.), Handbook of perception and human performance: Vol. 1. Sensory processes and perception (pp. 6-1 to 6-43). New York: Wiley.

Watson, A. B., Nielsen, K. R., Poirson, A., Fitzhugh, A., Bilson, A. Nguyen, K., \& Ahumada, A. J., JR. (1986). Use of a raster framebuffer in vision research. Behavior Research Methods, Instruments, \& Computers, 18, 587-594.

Whitt le, P. (1986). Increments and decrements: Luminance discrimination. Vision Research, 26, 1677-1691.

WhitT LE, P. (1991). Sensory and perceptual processes in seeing brightness and lightness. In A. Valberg \& B. Lee (Eds.), From pigments to perception: Advances in understanding visual processes (pp. 293304). New York: Plenum.

Whitt Le, P. (1992). Brightness, discriminability and the "crispening effect." Vision Research, 32, 1493-1507.

Whittle, P., \& Challands, P. (1969). The effect of background luminance on the brightness of flashes. Vision Research, 9, 1095-1110.
WiLson, H. R. (1997). A neural model of foveal light adaptation and afterimage formation. Visual Neuroscience, 14, 403-423.

Wolfson, S. S., \& GRAHAM, N. (2000). Exploring the dynamics of light adaptation: The effects of varying the flickering background's duration in the probed-sinewave paradigm. Vision Research, 40, 2277 2289.

Wolfson, S. S., \& Graham, N. (2001). Comparing increment and decrement probes in the probed-sinewave paradigm. Vision Research, 41, 1119-1131.

Woodward, J. A., Bonett, D. G., \& Brecht, M. L. (1990). Introduction to linear models and experimental design. New York: Harcourt Brace Jovanovich.

Yeh, T., Lee, B. B., \& Kremers, J. (1996). The time course of adaptation in Macaque retinal ganglion cells. Vision Research, 36, 913-931.

(Manuscript received December 30, 1999;

revision accepted for publication September 25, 2000.) 